\title{
The impact of land use and cover change on above and below-ground carbon stocks of the miombo woodlands since the 1950s: a systematic review protocol
}

\author{
Stephen Syampungani ${ }^{1 *}$, Jessica Clendenning ${ }^{2}$, Davison Gumbo ${ }^{3}$, Robert Nasi ${ }^{2}$, Kaala Moombe ${ }^{3}$, Paxie Chirwa ${ }^{4}$, \\ Natasha Ribeiro ${ }^{5}$, Isla Grundy ${ }^{6}$, Nalukui Matakala', Christopher Martius², Moka Kaliwile ${ }^{3}$, Gillian Kabwe ${ }^{1}$ \\ and Gillian Petrokofsky ${ }^{7}$
}

\begin{abstract}
Background: Increasingly, forests are on the international climate change agenda as land use and cover changes drive forest and carbon loss. The ability of forests to store carbon has created programs such as Reducing Emissions from Deforestation and Degradation plus (REDD+), in order to provide incentives for particular land uses and forest management practices. A critical element to REDD+ is the ability to know the carbon-storage potential of an ecosystem, and the factors likely to affect the rate of carbon accumulation or the maximum amount stored. Most REDD+ initiatives have focused on humid tropical forests because of their large stocks per unit area. Less attention has been paid to the carbon-storage potential of tropical dry forests, woodlands and savannas. Although these ecosystems support a lower biomass per unit area, they are more widespread than humid forests. This proposed systematic review examines miombo woodlands, which are the most extensive vegetation formation in Africa and support over 100 million people. We ask: To what extent have changes in land use and land cover influenced above- and below-ground carbon stocks of miombo woodlands since the 1950s?

Methods: We will search systematically for studies that document the influence of land use and cover change on above and below ground carbon in miombo woodlands since the 1950s. We will consult bibliographic databases and an extensive grey literature network, including government reports and forestry offices. Relevant studies will examine the impacts of human activities, fire and other land use or cover changes that affect wood biomass or soil carbon in the miombo region. All included studies will be assessed for the soundness and scientific validity of their study design. A quantitative synthesis will tabulate estimates of various parameters necessary to assess carbon stocks and changes across climate and geological factors; and a qualitative analysis will describe the governing land and forest policies. Understanding the impact that land uses and the associated changes have on carbon storage in the miombo woodlands will contribute to more informed forest management policies and better guided strategies for the United Nations Framework Convention on Climate Change.
\end{abstract}

Keywords: Miombo woodlands, REDD+, Woodfuel, Habitat degradation, Land use, Climate change, Carbon, Biomass, Land use practices

\footnotetext{
*Correspondence: syampungani@cbu.ac.zm

${ }^{1}$ Department of Environmental and Plant Sciences, Copperbelt University, Box 21692, Kitwe, Zambia

Full list of author information is available at the end of the article
} 


\section{Background}

The atmospheric concentration of carbon dioxide $\left(\mathrm{CO}_{2}\right)$ is on the rise. Changes in land use - including forest clearance for agriculture, settlement and industrial expansion have contributed about $136( \pm 55) \mathrm{Gt} \mathrm{C}$ or one-third of total anthropogenic emissions of $\mathrm{CO}_{2}$ to the atmosphere over the past 150 years [1,2]. The importance of $\mathrm{CO}_{2}$ to climate change has provided the impetus for research on the global carbon cycle with particular attention on carbon stocks in the main terrestrial compartments, mainly soils and plant biomass [3,4]. Various carbon initiatives have been designed to provide innovative ways for reducing the release of greenhouse gases and to increase carbon storage in various ecosystems: Reducing Emissions from Deforestation and Forest Degradation and enhancement of carbon stocks through forest conservation and sustainable management (REDD+) is one such an initiative. The purpose of REDD+ is to create an incentive for developing countries to protect, better manage and wisely use their forest resources, thereby contributing to the global fight against climate change. One critical element for the REDD+ mechanism is the ability to know the carbonstorage potential of a forest ecosystem, and the factors likely to affect both the rate of carbon accumulation and the maximum amount of carbon that can be stored. To date, most nascent REDD+ initiatives have focused on tropical moist forests because of their large carbon stocks per unit area (see [5]) and the substantial emissions of greenhouse gases that would result from converting these forests to pastures, cropland, or commercial timber plantations. Much less attention has been paid to the potential for reducing emissions from, and potential carbon storage in, dry forests and woodlands [6-8]. Although these systems support a much lower and more variable woody biomass per unit area [5], they are more widespread than tropical moist forests [6,9]. This is especially so in Africa, where land supporting, or capable of supporting, dry forests and woodlands cover approximately 8,592,420 $\mathrm{km}^{2}$ in contrast to the $3,479,180 \mathrm{~km}^{2}$ of dense and mosaic forest [10].

The miombo region encompasses a complex of vegetation formations each dominated by one or a few tree species in the legume subfamily Caesalpinioideae. Miombo woodlands are the most widespread and are dominated by species in the genera Brachystegia, Julbernardia and Isoberlinia on a wide range of acid, infertile, and generally medium-textured soils. Interspersed with the miombo woodlands, or situated towards the periphery of the region, are a number of structurally-similar vegetation formations each associated with particular edapho-climatic conditions. These include woodlands and open forest formations dominated by Baikiaea plurijuga on nutrientpoor, well-drained Kalahari sand; Marquesia macroura (Family Dipterocarpaceae) on deep, well-drained sandy loams in the high rainfall zone; Cryptosepalum pseudotaxus on sands with seasonally high water tables; and Colophospermum mopane on arid, alkaline, often nutrient-rich Triassic shales and shallow basaltic loams. Pockets of mixed woodland (called munga in Central Africa) dominated by Acacia, Combretum and Terminalia spp occur within miombo on limestone-derived loams and in the major river valleys on clay-rich alluvium, often alongside mopane woodlands and shrub lands.

Miombo woodlands support the livelihoods of over 100 million rural and urban dwellers through the provision of timber and non-timber forest products (NTFPs) such as bees wax, honey, edible fruits, edible insects, mushrooms and traditional medicines $[11,12]$. More than $80 \%$ of the rural population derive their livelihoods from the woodlands through permanent and shifting cultivation, charcoal and timber production, and the harvesting and sale of NTFPs $[11,13]$. Human activities are resulting into woodland degradation and cover loss, as well as loss in fauna, flora and woodland ecosystems [14]. The miombo woodlands, like many vegetation formations associated with them, are extensively disturbed, with little intact or oldregrowth woodland remaining and tree cover continuing to decline as a result of these poor land management practices [15]. Consequently, there has been a downward trend in the carbon stock of forest biomass in many miombo countries [16] (see Table 1). Considering the need to protect woodlands and support local livelihoods in the region, a convincing case can be made for extending REDD+ initiatives into the dry forests and woodlands of Africa.

As a result of mixed intensive and extensive land uses, miombo woodlands have varied land cover. While some of the woodlands are composed of tall, almost closedcanopy stands, other areas are cleared for shifting cultivation and charcoal production [17]. These variations in land cover influence how much biomass and carbon the woodlands can hold. Soil organic carbon (SOC) content, for instance, is reduced by cultivation and wood harvesting. A comparative study between the relatively undisturbed woodland and disturbed woodland in the Zimbabwean miombo revealed significant variation in soil carbon [18]. The findings show that organic carbon content was largest under reference (relatively undisturbed) woodlands on red clays (53.3 $\mathrm{Mg} \mathrm{C} \mathrm{ha}^{-1}$ ) followed by those on granitic sand (22.8 $\mathrm{Mg} \mathrm{C} \mathrm{ha}^{-1}$ ) and least on Kalahari sand (19.5 $\mathrm{Mg} \mathrm{C}^{-1}$ ). Organic carbon declined rapidly under cultivation, reaching new equilibria within a decade on all smallholdings. The high levels of woodland conversion per year results in soil degradation, erosion and loss of organic matter, which in turn enables the soil to have a higher potential to sequester carbon. Similarly, in terms of biomass, reductions of up to $38 \mathrm{Mg} \mathrm{ha}^{-1}$ occur with the clearance of woodlands for shifting cultivation [19]. Recorded rates of biomass increase in 
Table 1 Trends in carbon stock in living forest biomass: selected miombo countries 1990-2010 [16]

\begin{tabular}{|c|c|c|c|c|c|c|c|}
\hline \multirow[t]{2}{*}{ Country } & \multicolumn{4}{|c|}{ Carbon stock in living forest biomass $\left(10^{6} \mathrm{Mg}\right)$} & \multicolumn{3}{|c|}{ Annual changes $\left(10^{3} \mathrm{Mg} \mathrm{yr}^{-1}\right)$} \\
\hline & 1990 & 2000 & 2005 & 2010 & $1990-2000$ & 2000-2005 & $2005-2010$ \\
\hline Angola & 4573 & 4479 & 4432 & 4385 & -9 & -9 & -9 \\
\hline Malawi & 173 & 159 & 151 & 144 & -1 & -2 & -1 \\
\hline Mozambique & 1878 & 1782 & 1733 & 1692 & -10 & -10 & -8 \\
\hline Zimbabwe & 697 & 594 & 543 & 492 & -10 & -10 & -10 \\
\hline Zambia & 2579 & 2497 & 2457 & 2416 & -8 & -8 & -8 \\
\hline
\end{tabular}

some young regenerating miombo woodlands are $1.4-$ $1.8 \mathrm{Mg} \mathrm{ha}^{-1}$ [20-22].

Many studies across the miombo region have shown that woodlands can recover rapidly from disturbances caused by human activities, for example in Zambia [23-25]; Tanzania [26,27]; Zimbabwe [28,29] and Mozambique [30]. Luoga et al. [29] and Syampungani [19] have reported higher capacity to re-sprout/regenerate in harvested stands compared to mature, more or less untouched stands suggesting that miombo woodlands are dynamic ecosystems reacting well to appropriate levels of exploitation. Like many other dry forest and woodland species, miombo woodland tree species have extensive vertical and horizontal root systems which facilitate regeneration after cutting $[31,32]$. The availability of stump coppices, root suckers, or suppressed saplings in the herb layer at the time of clearing $[19,33]$ enables the woodlands to recover rapidly, depending on the intensity of subsequent land use (e.g. cultivation).

Currently, there are a number of emerging international and private sector finance schemes and policies intended to support livelihoods, poverty alleviation and sustainable growth through carbon sequestration projects in the miombo region [34]. Examples of carbon projects that have been undertaken within the miombo ecoregion include the N'hambita Carbon Project, Mozambique, now called the Gorongosa Community Carbon sub-Project [35], and the Mpingo Conservation and Development Initiative, Tanzania [36]. However, other countries within the miombo ecoregion are also in the process of implementing REDD+ projects. These initiatives are aimed at developing forestry and land use practices that promote sustainable rural livelihoods in participation with rural communities in a way that raises their living standards, and to assess the potential of these initiatives in generating verifiable carbon emission reductions.

We therefore aim to undertake a review that will help develop an understanding of the impacts land use and land cover changes have on wood biomass and carbon stocks in miombo. To do this, we will systematically identify, appraise and synthesize the available literature on wood biomass and soil carbon stocks in miombo woodlands e.g. [37-39]. Our review will focus on the available studies that show direct impacts of land use and land cover changes on above and below ground carbon stocks in the miombo woodlands over time. Some of the factors associated with these changes include anthropogenic disturbances (i.e., agriculture, wood harvesting, and infrastructure development) and fire [11] which are likely to be exacerbated by climate change. The conceptual model, shown below, represents how land use and land cover change is thought to impact on above-and below-ground carbon stocks in the miombo woodlands. Adapted from PGH Frost, personal communication, January 22, 2014 (Figure 1).

\section{Objective of the review \\ Primary question}

What has been the impact of changes in land use and land cover on above- and below-ground carbon stocks of miombo woodlands since the 1950s?

\section{Supporting questions}

- What are the drivers of woodland degradation and how do they contribute to biomass and carbon stock (wood and soil) changes in the miombo woodlands?

- How do different land use practices impact on wood biomass and soil carbon stocks across the miombo woodlands?

- What have been the impact of policy and institutional frameworks to the maintenance and management of wood biomass and carbon stocks in the miombo woodlands?

\section{Methods}

\section{Author and stakeholder workshops}

The miombo review team held two author and stakeholder workshops on November 26-27, 2013 in Livingstone, Zambia, and on January 21-22, 2014 in Lusaka, Zambia. Each workshop had the main review team plus additional authors, advisors, or other stakeholders engaged in research and policy issues concerning miombo woodlands. The November 2013 workshop concentrated on sharpening the scope of the study, defining the primary research questions, and discussing the types and availability of data for the miombo region. The January 2014 workshop focused on improving the links between the protocol's 


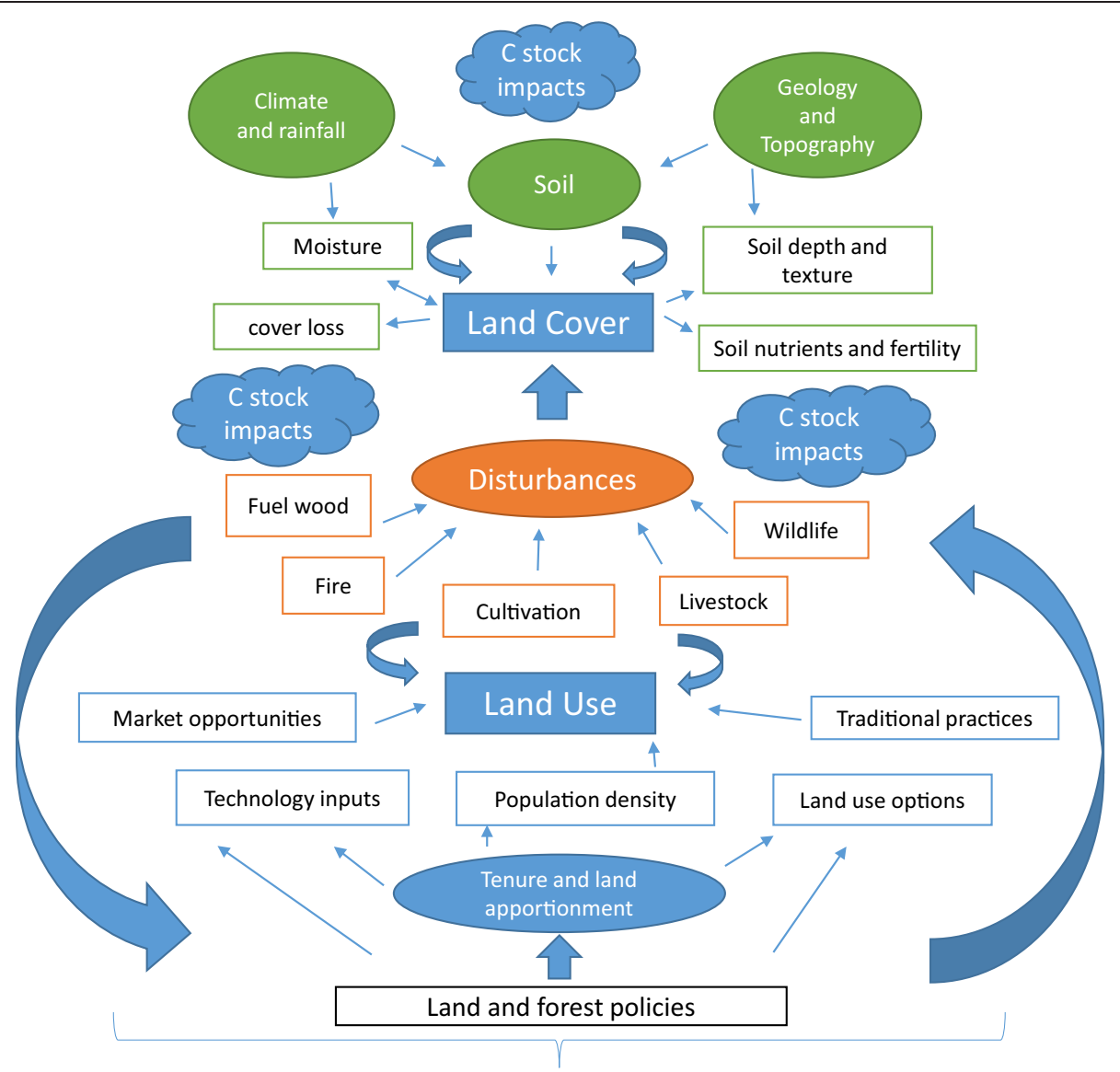

Figure 1 Impacts of land use and cover change on above-and below-ground carbon stocks in the miombo woodlands.

background and outcome sections, and developing data extraction and quality assessment criteria. Both workshops served to further refine the review's focus for understanding how land use and cover changes in the miombo region (and globally, dry forests) affect carbon fluxes.

\section{Scope and search strategy}

Our review will include peer-reviewed and grey literature from 1950 onwards on changes in biomass and carbon stocks under different land use practices in miombo woodlands. We will also consider reviewing literature before 1950 that can provide useful baseline information for the study. Our search strategy will combine the survey population (miombo woodlands, tree species and relevant countries), exposure (types of land use), and outcomes on wood biomass or carbon (above-and below-ground) (see Table 2 below). Preliminary searching in CAB Direct [40], Scopus [41] and Web of Knowledge (WoK) [42] took place in January and April to determine the size of the literature base and appropriate search combinations. $C A B$ Thesaurus [43] was used to decide on compound search terms, such as "land degradation", "land policy" and "forest management". Scoping searches were trialled in Scopus and WoK, which produced approximately 5 to 6 thousand hits. The search string was refined further in August 2014, by deleting redundant or generic search terms that produced irrelevant results. Additionally, a reference list of 20 relevant studies was created to test for search comprehensiveness (discussed below). Table 2 outlines the main and expanded terms used for searching bibliographic databases and related forestry and agriculture websites.

\section{Search combinations}

The main bibliographic databases will use the following search string:

1 AND 2 AND 3 AND 4 (from Table 2)

As databases and search engines vary in the algorithms used to find studies, some search strings will be shortened and simplified. For instance, searches performed on websites or research forums will only use a few of the key words from the Population, Exposure and Outcome terms, such as "miombo woodlands", "land use" and "carbon OR biomass". All search combinations, their corresponding database or website, and the date when 
Table 2 Search terms

\section{Population}

1. Miombo woodland

2. Countries

\section{Exposure}

3. Land use miombo OR woodland* OR "Zambez* phytoregion" OR brachystegia OR julbernardia OR isoberlinia OR savanna* OR forest* OR "standing stock" OR biomass

Zambia OR Angola OR Malawi OR "Democratic Republic of Congo" OR Mozambique OR Zimbabwe OR Tanzania OR "South Africa" OR Burundi OR "Belgian Congo" OR Zaire OR Rhodesia OR Nyasaland OR Tanganyika OR Africa

Outcome

4. Wood OR biomass OR carbon emission* OR vegetation OR wood* OR biomass OR carbon OR stock* OR flux* OR "above ground" OR "below ground" OR "basal area" OR sequest* OR accumulate* OR model OR estimat* OR ndvi* OR recover* OR "land use change"++ OR rootstock

*is used to retrieve variations on a word stem or root. + - "slash and burn" is also searched slash NEAR burn.

++ "land use change is also searched as "land use" NEAR change.

searches were performed will be recorded and included in an Appendix of the full review.

\section{Search comprehensiveness}

To ensure our search strategy was robust and comprehensive, we selected 20 articles (see Additional file 1) of known relevance to the miombo review. These articles were developed and used during two stakeholder and author workshops in November 2013 and January 2014. In a series of trial searches using Scopus, WoK and CAB Direct, all twenty articles were found in $C A B$ (with approximately 4,321 results), 19 out of 20 were found in Scopus (out of approximately 5,891 results) and 18 out of 20 were found in WoK (out of approximately 5,867 results). Additional file 2 shows the full search strings used in Scopus, CAB Direct and WoK.

\section{Publication databases}

We will use the following publication databases and search engines to search for relevant literature:

- Archive of Tropical Forestry Inventory (ATROFI-UK) [44]

- Electronic Data Information Source (EDIS) [45]

- CAB Direct [40]

- Natural Resources Canada (NRCan) Library Catalogue [46]

- Web of Knowledge (WoK) [42]

- Scopus [41]

- Wiley Online [47]

- JSTOR [48]

\section{Search engines}

- Google Scholar [49]
Google Scholar will be used to identify any relevant papers missed by the bibliographic databases. As Google Scholar will most likely return a large number of hits, the first 100 results, sorted by relevance, will be checked for duplicates and inclusion.

\section{Organizations and websites that we will search or contact} We will obtain grey literature and unpublished studies on the miombo woodlands from a range of research, government and non-government institutions active in the field, as listed below.

- African Forest Forum [50]

- Food and Agricultural Organization (FAO) [51]

- The Consultative Group on International Agricultural Research (CGIAR) [52]

- Global Forest Resources Assessment (FRA) (2005; 2010 country reports) [53]

- United Nations Environment Programme (UNEP) [54]

- Tropical Soil Biology and Fertility Institute of CIAT (TSBF-CIAT): Conservation and sustainable management of below ground biomass project [55]

- National Forest Monitoring and Assessment (NFMA) of the FAO [56]

- Miombo Network list serve [57]

- Commonwealth Scientific Industrial Research Organisation (CSIRO) [58]

- The World Bank [59]

- Integrated Land Use Assessment Phase 1 \& 2, Zambia [60]

- National vegetation Mapping projects (VegRIS) - Zimbabwe [61]

- Winrock International [62]

- KEW Royal Botanic Gardens [63] 
- Land and Timber Services (LTS) International [64]

- Japan's International Cooperation Agency (JICA) (Mozambique information) [65]

- Deutsche Gesellschaft für Internationale Zusammenarbeit GmbH (GIZ) [66]

- Multifunctional Agriculture: Harnessing Biodiversity for Sustainable Agricultural Production and Ecosystem Services (SAPES), Lund University [67]

- Total Land Care - Malawi [68]

- Conservation International (CI) [69]

- World Wildlife Fund (WWF) [70]

- International Union for the Conservation of Nature (IUCN) [71]

- National Forestry Resources Monitoring and Assessment, Government of Tanzania (NA FORMA) [72]

- African Soil Information Service (Afsis) [73]

\section{Private sector}

Many private sector businesses conduct projects within the miombo region and have related historical data useful to this review. The review team will contact the following businesses for relevant studies.

- Agricultural Research and Extension Trust - Malawi

- British American Tobacco

- Alliance One - Malawi, Zambia

- Zambia Land Alliance

- Dunavant (cotton)

- Zambia Leaf

- Limbe Leaf - Malawi

\section{Universities and government offices}

Similarly, many university and government offices conduct research in miombo areas. The review team will contact the following university departments and government offices for studies.

- Forest Research Institute of Malawi

- Oxford Department of Plant Sciences

- Government departments in miombo countries

- Government departments in miombo countries including: Forestry; lands; agriculture; resettlement; mines; environment; and natural resources departments

- Tanzania Forest Research Institute

- Forestry Commission, Harare

- University of Zimbabwe, Institute of Environmental Studies, and the Centre for Applied Social Science (CASS)

- Bangor University

- University of Sokoine, Department of Agriculture, Tanzania

- University of Zambia, School of Natural Sciences \& Agricultural Sciences
- University of Edinburgh, School of Geosciences

- University of Aberdeen, Forestry \& Agriculture Department

- Climate Action Network International

- Southern Alliance for Indigenous Resources

- National University of Science and Tech, GIS mapping \& Inventory at Forest Research Centre, Bulawayo, Zimbabwe

- Environmental Management Agency (EMA), Harare

- Zambia Environmental Management Agency (ZEMA)

- Ministry for Coordination of Environmental Action (MICOA)

- Department of Environmental Affairs, Malawi

- Wildlife Management Institutions

- Natural History Museums

\section{Study inclusion process and criteria}

After all the literature has been captured and the duplicates removed, at least two reviewers will screen the articles for relevance at title, abstract and full text. To begin, a Kappa analysis will be performed on a random sample (minimum of 100) of the titles to measure the level of agreement between the two (or more) reviewers and their application and understanding of the inclusion criteria (Table 3). If the kappa is lower than 0.6, reviewers will discuss the discrepancies and clarify any differences in interpretation of the inclusion criteria, and perform another Kappa analysis on an additional random sample until a score of 0.6 or above is reached. The reviewers will separate the titles, abstracts, and full text studies into groups and screen their respective sections separately, with all work saved for additional checking if needed. The screening done at title and abstract stages will be conservative to ensure that any questionable study will be included for further assessment of the full text. All reasonable effort will be made to obtain the full text of individual studies by contacting the authors or institutions electronically or by letter.

The screening process will be recorded to show how many articles were excluded at the title, abstract and full text stages. Justification for excluding articles at the final stage will be documented and included in an appendix of the full review.

Study relevance will be determined using the inclusion criteria presented in Table 3.

For inclusion, each study must demonstrate it is within the miombo region by the described tree species, document the relevant exposures and describe how these changes have impacted on above-or below-ground carbon stocks or plant biomass. We will review studies that examine the correlation between vegetation density and above-ground living wood volume measured in diameter at breast height (DBH). This measurement is then 
Table 3 The subjects, exposures, comparators and outcomes of relevance

\begin{tabular}{|c|c|c|c|}
\hline Relevant subject & Relevant exposures & Comparators & Relevant outcomes \\
\hline \multirow{15}{*}{$\begin{array}{l}\text { Miombo woodlands: as defined } \\
\text { by the presence of Brachystegia, } \\
\text { Julbernardia and Isoberlinia }\end{array}$} & Land use and land use practices & \multirow{15}{*}{$\begin{array}{l}\text { Alternative land uses and } \\
\text { practices compared either as } \\
\text { controlled 'plots' (study areas } \\
\text { defined in the primary studies) } \\
\text { with different land-use strategies } \\
\text { set up and analysed at the } \\
\text { same time, or before-and-after } \\
\text { intervention comparisons on the } \\
\text { same plots. }\end{array}$} & \multirow{15}{*}{$\begin{array}{l}\text { Any measured change in: } \\
\text { - Carbon stocks (including plant } \\
\text { carbon and soil carbon) } \\
\text { - Plant biomass (including above } \\
\text { and below ground) }\end{array}$} \\
\hline & $\begin{array}{l}\text { ground carbon stocks, which } \\
\text { include: }\end{array}$ & & \\
\hline & $\begin{array}{l}\text { - Energy use (firewood and } \\
\text { charcoal) }\end{array}$ & & \\
\hline & - Poles (for use in the home) & & \\
\hline & - Commercial Timber harvesting & & \\
\hline & $\begin{array}{l}\text { - Agriculture (including shifting } \\
\text { cultivation, expansion) }\end{array}$ & & \\
\hline & - Livestock (browsing of saplings) & & \\
\hline & - Wildlife damage (i.e. elephants) & & \\
\hline & $\begin{array}{l}\text { - Beekeeping (making of } \\
\text { traditional bark hives) }\end{array}$ & & \\
\hline & $\begin{array}{l}\text { - Destructive harvesting of NTFPs } \\
\text { (e.g., edible caterpillars, fruits) }\end{array}$ & & \\
\hline & - Protected areas & & \\
\hline & - Agroforestry & & \\
\hline & $\begin{array}{l}\text { - Fire (natural; managed and } \\
\text { wild) }\end{array}$ & & \\
\hline & $\begin{array}{l}\text { - Rainfall; drought; temperature } \\
\text { variability }\end{array}$ & & \\
\hline & $\begin{array}{l}\text { - Infrastructure development } \\
\text { (roads; mining) }\end{array}$ & & \\
\hline
\end{tabular}

converted to tons of carbon per hectare ( $\mathrm{tC} / \mathrm{ha}$ ). In addition, studies that address local to regional level policies and institutional issues in the miombo region will be included in the review.

\section{Relevant types of study or experimental designs}

1. Studies that compare alternative land uses and practices (see Table 3) either as controlled 'plots' (study areas defined in the primary studies) with different land-use and practice strategies set up and analysed at the same time, or before-and-after intervention comparisons on the same plots. Studies will be included if they contain a clear description of the sample site(s), methods and measurements used for biomass estimation (there is no minimum number or size of sample sites) and give empirical information from the miombo region on either of the following:

- Studies that measure carbon changes/fluxes in above-and below-ground carbon pools

- Studies that measure above-and below-ground carbon storage

2. We will also include studies that link land use and biomass or carbon change to associated land or forest management policies, tenure arrangements, or land allocation decisions in the miombo. These studies, which will be analysed separately, will not be limited to those reporting empirical results.

Following feedback from stakeholders, we judge it important to include these studies to understand the context of policy decisions and change within the miombo region. Care will be taken to avoid study replication, as we are aware that many secondary data sources will use data gained from the same primary study.

Excluded study designs include:

- Studies outside of the miombo (as described by the inclusion criteria)

- Studies without biomass or carbon measurements

\section{Critical appraisal of study quality and potential effect modifiers}

Studies included in the review after full text screening will be critically appraised for the robustness of their study design and the extent to which authors attempted to limit biases. The following variables will be assessed: study length, study timescale, replication, sources of potential bias, level of documented methodological detail, and additional information listed in Table 4. The review will also look at the comparator types and appropriateness. For example, were control plots, abandoned lands 
Table 4 Additional variables captured for critical appraisal

\begin{tabular}{l}
\hline Contextual social information \\
\hline 1. Does the information presented set the study's historical \\
context? \\
2. Does the information presented set the study's ecological \\
context? \\
3. Is there information on the political context for the \\
duration of the study? \\
Site and population information \\
4. Does study provide information on site characteristics at \\
the time of the study? \\
- Soil \\
- Climate \\
- Is account taken of seasonality? \\
- Is site vegetation documented?
\end{tabular}

or protected areas used as comparators? Further, the review team is aware of the proposal by Bilotta et al. [74] that environmental systematic reviews should adapt the Environmental-Risk of Bias Tool and we will check the feasibility of this approach for our set of studies. We know that our review will include a number of older, and in some cases unpublished, studies and we are also aware of advances in study design in recent decades and of the general problem of pseudo replication in studies [75]. Accordingly, we will amend our proposed critical appraisal method if it is too difficult to apply by reviewers (requiring subjective judgement that is difficult to standardise across reviewers, despite repeated kappa analysis). The criteria will be sorted into high, medium and low quality studies. High quality studies will demonstrate appropriate levels of methodological detail (including 'yes' to all of the questions in Table 4), while medium quality studies will answer $70 \%$ of the appraisal questions. Low quality studies that demonstrate major deficiencies in attention to principles of research quality will be removed and archived. Amendments to our appraisal method will be discussed with our Advisory Board and published online at CIFOR's Evidence-Based Forestry website [76] to ensure transparency.

Several factors can influence study results on biomass and carbon measurements, from biophysical changes in soil and rainfall to anthropogenic disturbances. We will investigate, to the extent possible, the strongest effects on any measured outcome. Potential effect modifiers will be recorded for studies included in the review.

\section{Data extraction strategy}

After an included study has passed critical appraisal, two reviewers will extract the quantitative and qualitative data needed for the review. Additional checks will be carried out on $25 \%$ of each reviewer's extracted data to ensure the information is recorded in a consistent manner.
Extracted information on each study will be recorded using an electronic data extraction form. The twenty key references found in Additional file 1 will be used to test and improve the data extraction form. The data to be extracted will follow a similar format as other environmental systematic reviews, described below and adapted from Roe et al. and Pullin and Knight [77,78]. Data to be extracted will include:

- Bibliographic information: author, year, title, publication, place of publication, publisher

- Basic study information: location of study, exposure (s), duration of the exposure(s)

- Details of evidence type: source, study design, methodology, parameters used in the analysis, duration of study

- Relevant detail considered in the study: conceptual link between the exposure and biomass or carbon stock

- Details of outcomes: reported effect on biomass and carbon, duration of impacts, scale and suitability of impacts

If a study has insufficient data or missing information (i.e., missing baseline or reference conditions for a given site) that makes it difficult to use the data, the reviewers will first try to contact the authors for additional information. If the data is unavailable or not usable within the review (as decided by the review team), then the study will be excluded and noted as an outcome of the review process.

\section{Synthesis and presentation}

This review will use both quantitative and qualitative syntheses to understand the impacts that human (i.e., land use changes) and non-human (i.e., fire, wildlife, etc.) activities have on biomass and soil carbon in the miombo. A quantitative analysis will tabulate the extracted variables of mean root: shoot ratios, mean basal area, mean stocking $\mathrm{ha}^{-1}$, mean biomass (above and below ground biomass), carbon density, together with the standard deviations about the means and the associated sample sizes. The estimates of the above parameters will be compared with different exposures and controls of varying climate/rainfall, topography, and soil-physical characteristics. If sufficient information is provided, the review team will conduct a meta-analysis in addition to a narrative synthesis.

The qualitative synthesis will analyse words and text to summarise the effectiveness of policy and institutional processes governing land use and cover change in the miombo region [79]. This narrative analysis will use descriptive studies to examine the connections between the legal status of land (e.g., protected, communal or game areas), the regional land and forest policy environment, 
and the associated land use and cover changes over time. We will link both the quantitative and qualitative analyses with statistical and descriptive accounts of any potential parallels, shifts or relationships of land use and land cover change over the past sixty years in the miombo woodlands.

\section{Additional files}

\section{Additional file 1: 20 reference articles to test search comprehensiveness.}

Additional file 2: Search strings used in CAB, Scopus and Web of Knowledge databases.

\section{Competing interests}

The authors declare that they have no competing interests.

\section{Authors' contributions}

SS drafted the protocol and led the review's coordination. JC led the scoping study, facilitated the workshops, drafted the methods section and provided feedback on the protocol. DG organized the workshops and provided input to the protocol. RN conceived the study and provided feedback on numerous drafts of the protocol. PC, CM, NR and GK all gave input and comments on earlier drafts of the protocol. KM, NM, and MK provided research summaries for the background section of the protocol. GP gave input on the methodology and design of the protocol. All authors read and approved the manuscript.

\section{Acknowledgements}

This protocol and forthcoming review are financed from the United Kingdom's Department for International Development (DfID) through CIFOR's Evidence-Based Forestry Initiative. The authors would like to thank all advisory team members, authors, and stakeholders for their invaluable time and advice during workshops and through drafts of the protocol. Special thanks to Peter Frost for his generous intellectual contributions and editing skills. Similar thanks to three anonymous reviewers for their suggestions and critical feedback. All of these efforts have improved this protocol considerably.

\section{Author details}

${ }^{1}$ Department of Environmental and Plant Sciences, Copperbelt University, Box 21692, Kitwe, Zambia. ${ }^{2}$ Center for International Forestry Research, (CIFOR), Jalan CIFOR, Situ Gede, Sindang Barang, Bogor 16115, Indonesia. ${ }^{3}$ Center for International Forestry Research, (CIFOR), Forestry Nursery Site, 4019 Elm Road, Lusaka, Zambia. ${ }^{4}$ University of Pretoria, Faculty of Natural and Agricultural Sciences, Room 4-11, Lynwood Road, Pretoria 0002, South Africa. ${ }^{5}$ Department of Forestry, Eduardo Mondlane University, Box 257, Maputo, Mozambique. ${ }^{6}$ Department of Biological Sciences, University of Zimbabwe, PO Box MP 167, Mt Pleasant, Harare, Zimbabwe. ${ }^{7}$ Department of Zoology, University of Oxford, The Tinbergen Building, South Parks Road, Oxford OX1 3PS, UK.

\section{Received: 17 April 2014 Accepted: 13 October 2014}

Published: 5 December 2014

\section{References}

1. Watson R, Noble I, Bolin B, Ravindranath N, Verardo D, Dokken D: Land Use, Land-Use Change and Forestry: a Special Report of the Intergovernmental Panel on Climate Change. Cambridge, UK: Cambridge University Press; 2000.

2. Eggleston S, Buendia L, Miwa K, Ngara T, Tanabe K: IPCC Guidelines for National Greenhouse Gas Inventories. Hayama, Japan: Institute for Global Environmental Strategies; 2006.

3. Mackey B, Prentice IC, Steffen W: Untangling the confusion around land carbon science and climate change mitigation policy. Nat Clim Chang 2013, 3:552-557.

4. Henry M, Valentini R, Bernoux M: Soil carbon stocks in ecoregions of Africa. Biogeosci Discuss 2009, 6:797-823.
5. Assessment ME: Ecosystems and Human Well-Being. Washington, DC: Island Press; 2005.

6. Chidumayo E, Marunda C: Dry Forests and Woodlands in Sub-Saharan Africa: Context and Challenges. In The dry Forests and Woodlands of Africa: Managing for Products and Services. Edited by Chidumayo E, Gumbo D. London: Earthscan; 2010:1-10.

7. Day M, Gumbo D, Moombe KB, Wijaya A, Sunderland T: Zambia Country Profile: Monitoring, Reporting and Verification for REDD+. Bogor, Indonesia: Center for International Forestry Research; 2014.

8. Sanchez-Azofeifa GA, Kalacska M, Quesada M, Calvo-Alvarado JC, Nassar JM, Rodriguez JP: Need for integrated research for a sustainable future in tropical dry forests. Conserv Biol 2005, 19:285-286.

9. Blackie R, Baldauf C, Gautier D, Gumbo D, Kassa H, Parthasarathy N, Paumgarten F, Sola P, Pulla S, Waeber P, Sunderland T: Tropical dry Forests: the State of Global Knowledge and Recommendations for Future Research. Bogor, Indonesia: Center for International Forestry Research; 2014.

10. Bodart C, Brink AB, Donnay F, Lupi A, Mayaux P, Achard F: Continental estimates of forest cover and forest cover changes in the dry ecosystems of Africa between 1990 and 2000. J Biogeogr 2013, 40:1036-1047.

11. Dewees $P$, Campbell B, Katerere $Y$, Sitoe A, Cunningham A, Angelsen A, Wunder S: Managing the miombo woodlands of southern Africa: policies, incentives and options for the rural poor. $J$ Natural Resources Policy Res 2010, 2:57-73.

12. Cumming D, Guveya E, Matose F: A Framework for Examining SocialEcological Linkages in the Conservation of the Miombo Eco-Region. Harare, Zimbabwe: World Wildlife Fund-Southern Africa Regional Programme Office; 2002

13. Campbell B, Angelsen A, Cunningham A, Katerere Y, Sitoe A, Wunder S: Miombo Woodlands - Opportunities and Barriers to Sustainable Forest Management. Bogor, Indonesia: Center for International Forestry Research; 2007.

14. Schreckenberg $\mathrm{K}$, Awono A: Domesticating indigenous fruit trees as a contribution to poverty reduction. Forests, Trees and Livelihoods 2006, 16:35-51.

15. Timberlake J, Chidumayo E: Miombo Ecoregion Vision Report. Bulawayo, Zimbabwe: Biodiversity Foundation for Africa; 2011.

16. Syampungani S, Chirwa PW: Miombo Woodland Productivity: The Potential Contribution to Carbon Sequestration and Payment for Environmental Services in East and Southern Africa. In Woodlands: Ecology, Management and Conservation. Edited by Wallace EB. New York: Nova Scotia Publishers, Inc; 2011:187-201.

17. Chirwa PW, Syampungani S, Geldenhuys CJ: The ecology and management of the Miombo woodlands for sustainable livelihoods in Southern Africa: the case for non-timber forest products. Southern Forests: a J Forest Science 2008, 70:237-245 (239).

18. Zingore S, Manyame C, Nyamugafata P, Giller KE: Long-term changes in organic matter of woodland soils cleared for arable cropping in Zimbabwe. Eur J Soil Sci 2005, 56:727-736.

19. Syampungani S: Vegetation Change Analysis and Ecological Recovery of the Copperbelt Miombo Woodlands of Zambia PhD Thesis. University of Stellenbosch, Department of Forest Science; 2008.

20. Stromgaard P: Biomass, growth, and burning of woodland in a shifting cultivation area of South Central Africa. For Ecol Manage 1985, 12:163-178.

21. Walker SM, Desanker PV: The impact of land use on soil carbon in miombo woodlands of Malawi. For Ecol Manage 2004, 203:345-360.

22. Williams M, Ryan CM, Rees RM, Sambane E, Fernando J, Grace J: Carbon sequestration and biodiversity of re-growing miombo woodlands in Mozambique. For Ecol Manage 2008, 254:145-155.

23. Frost P: The Ecology of Miombo Woodlands. In The Miombo in Transition: Woodlands and Welfare in Africa. Edited by Campbell B. Bogor, Indonesia: Center for International Forestry Research; 1996:11-57.

24. Chidumayo EN: Miombo Ecology and Management: an Introduction. London: Intermediate Technology Publications Ltd (ITP); 1997.

25. Chirwa PW, Syampungani S, Geldenhuys CJ: Managing Southern African Woodlands for Biomass Production: The Potential Challenges and Opportunities. In Bioenergy from Wood: Sustainable Production in the Tropics, Managing Forest Ecosystems. Edited by Seifert T. Dordrecht: Springer; 2014:67-85.

26. Fanshawe D: The Vegetation of Zambia. Lusaka, Zambia: Government Printer; 1971. 
27. Chidumayo EN: Development of Brachystegia-Julbernardia woodland after clear-felling in central Zambia: evidence for high resilience. App/ Veg Sci 2004, 7:237-242

28. Boaler SB, Sciwale KC: Ecology of a miombo site, Lupa North Forest Reserve. Tanzania: III. Effects on the vegetation of local cultivation practices. J Ecol 1966, 54:577-587.

29. Luoga EJ, Witkowski ETF, Balkwill K: Regeneration by coppicing (resprouting) of miombo (African savanna) trees in relation to land use. For Ecol Manage 2004, 189:23-35

30. Strang RM: Some man-made changes in successional trends on the Rhodesian highveld. J Appl Ecol 1974, 11:249-263.

31. Grundy IM: Regeneration and Management of Brachystegia Spiciformis Benth And Julbernardia Globiflora (Benth.) Troupin in Miombo Woodlands of Zimbabwe. PhD Thesis. Oxford: University of Oxford, Department of Plant Sciences; 1995.

32. Geldenhuys CJ: Basic Guidelines for Silvicultural and Management Practices in Mozambique. Pretoria: FORESTWOOD, CC; 2005

33. Chidumayo EN: Responses of Miombo to Harvesting: Ecology and Management. Stockholm: Stockholm Environment Institute; 1993.

34. Stringer LC, Dougill AJ, Thomas AD, Spracklen DV, Chesterman S, Speranza Cl, Rueff $\mathrm{H}$, Riddell M, Williams M, Beedy T, Abson DJ, Klintenberg P, Syampungani S, Powell P, Palmer AR, Seely MK, Mkwambisi DD, Falcao M, Sitoe A, Ross S, Kopolo G: Challenges and Opportunities in Linking Carbon Sequestration, Livelihoods and Ecosystem Service Provision in Drylands. Environmental Science and Policy 2012, 19-20:121-135.

35. Gorongosa community carbon sub-project. http://cotap.org/projects/ sofala/.

36. Mpingo conservation and development initative. http://www. mpingoconservation.org/home/.

37. Chidumayo E, Frost P: Population Biology of Miombo Trees. In The Miombo in Transition: Woodlands and Welfare in Africa. Edited by Campbell B. Bogor, Indonesia: Center for International Forest Research; 1996:56-71.

38. Mistry J: World Savannas: Ecology and Human Use. Harlow: Prentice Hall; 2000.

39. Mapaure IN, Campbell BM: Changes in miombo woodland cover in and around Sengwa Wildlife Research Area, Zimbabwe, in relation to elephants and fire. Afr J Ecol 2002, 40:212-219.

40. CAB Direct. http://www.cabdirect.org/.

41. Scopus. http://www.scopus.com/.

42. Web of Knowledge (WoK). http://apps.webofknowledge.com/.

43. CAB Thesaurus. http://www.cabi.org/cabthesaurus/.

44. Archive of Tropical Forestry Inventory (ATROFI-UK). http://www.rdg.ac.uk/ ssc/atrofi.

45. Electronic Data Information Source (EDIS). http://edis.ifas.ufl.edu/

46. Natural Resources Canada (NRCan) Library Catalogue. http://www.nrcan. gc.ca/library/177

47. Wiley Online. http://onlinelibrary.wiley.com/

48. JSTOR. http://www.jstor.org/

49. Google Scholar. http://scholar.google.com.

50. African Forest Forum. http://www.afforum.org/.

51. Food and Agricultural Organization (FAO). http://www.fao.org/home/en/

52. The Consultative Group on International Agricultural Research (CGIAR). http://www.cgiar.org/resources/cgiar-library/.

53. Global Forest Resources Assessment (FRA). http://www.fao.org/forestry/ fra/en/.

54. United Nations Environment Programme (UNEP). http://www.unep.org/.

55. Tropical Soil Biology and Fertility Institute of CIAT (TSBF-CIAT): Conservation and sustainable management of below ground biomass project. http://www.cbd.int/kb/record/organization/5628?Country=ke.

56. National Forest Monitoring and Assessment (NFMA) of the FAO. http://www.fao.org/forestry/nfrms/en/.

57. Miombo Network list serve. http://www.fao.org/gtos/gofc-gold/networks. html.

58. Commonwealth Scientific Industrial Research Organisation (CSIRO). http://www.csiro.au/.

59. The World Bank. http://www.worldbank.org/

60. Integrated Land Use Assessment Phase 1 \& 2, Zambia. http://www.fao org/forestry/17847/en/zmb/.

61. National vegetation Mapping projects (VegRIS) - Zimbabwe. http://www forestry.co.zW

62. Winrock International. http://www.winrock.org/.
63. KEW Royal Botanic Gardens. http://www.kew.org/.

64. Land and Timber Services (LTS) International. http://www.ltsi.co.uk/

65. Japan's International Cooperation Agency (JICA). http://www.jica.go.jp/ english/.

66. Deutsche Gesellschaft für Internationale Zusammenarbeit GmbH (GIZ). http://www.giz.de/en/.

67. Sustainable Agricultural Production and Ecosystem Services (SAPES), Lund University. http://www.cec.lu.se/research/sapes.

68. Total Land Care - Malawi. http://www.totallandcare.org/

69. Conservation International (Cl). http://www.conservation.org/.

70. World Wildlife Fund (WWF). http://worldwildlife.org/.

71. International Union for the Conservation of Nature (IUCN). http://www. iucn.org/.

72. National Forestry Resources Monitoring and Assessment, Government of Tanzania (NA FORMA). http://www.fao.org/forestry/17847/en/tza/.

73. African Soil Information Service (Afsis). http://www.africasoils.net/.

74. Bilotta G, Milner A, Boyd I: Quality assessment tools for evidence from environmental science. Environmental Evidence 2014, 3:1-14.

75. Ramage BS, Sheil D, Salim HMW, Fletcher C, Mustafa NZA, Luruthusamay JC, Harrison RD, Butod E, Ahmad Dzamir D, Abd Rahman K, Potts MD: Pseudoreplication in tropical forests and the resulting effects on biodiversity conservation. Conserv Biol 2013, 27:364-372.

76. Evidence-Based Forestry (EBF), Center for International Forestry Research (CIFOR). http://www1.cifor.org/ebf/home.html.

77. Pullin A, Knight T: Effectiveness in conservation practice: pointers from Medicine and Public Health. Conserv Biol 2001, 15:50-54.

78. Roe D, Day M, Booker F, Zhou W, Allebone-Webb S, Kümpel N, Hill N, Wright J, Rust N, Sunderland TCH, Redford K, Petrokofsky G: Are alternative livelihood projects effective at reducing local threats to specified elements of biodiversity and/or improving or maintaining the conservation status of those elements? A systematic review protocol. Environmental Evidence 2014, 3:6

79. Pope C, Mays N, Popay J: Synthesising Quantitative and Qualitative Health Evidence: A Guide to Methods. Maidenhead, UK: Open University Press; 2007.

doi:10.1186/2047-2382-3-25

Cite this article as: Syampungani et al:: The impact of land use and cover change on above and below-ground carbon stocks of the miombo woodlands since the 1950s: a systematic review protocol.

Environmental Evidence 2014 3:25

\section{Submit your next manuscript to BioMed Central and take full advantage of:}

- Convenient online submission

- Thorough peer review

- No space constraints or color figure charges

- Immediate publication on acceptance

- Inclusion in PubMed, CAS, Scopus and Google Scholar

- Research which is freely available for redistribution 